\title{
A PAIXÃO DO NEUTRO
}

\author{
Alex Keine de Almeida Sebastião ${ }^{1}$
}

\begin{abstract}
Resumo
Trata-se de examinar a experiência narrada no livro A paixão segundo G.H., de Clarice Lispector, sob uma perspectiva que reúne dois planos: o da protagonista e o da própria escrita. Buscamos acompanhar a jornada de G.H. em seu encontro com a barata e consigo mesma e, ao final, recorremos à noção de neutro, presente na teoria literária de Maurice Blanchot, para propor que a paixão do neutro é uma forma de descrever a paixão de G.H..
\end{abstract}

\section{Palavras-chave}

Neutro. A paixão segundo G.H.. Clarice Lispector.

Em A paixão segundo G.H., de Clarice Lispector, acompanhamos a narradora ao longo de uma experiência radical de confrontação com os limites da subjetividade, do humano e da realidade. O encontro com a barata sustenta uma sucessão de sensações e pensamentos que constituem um mergulho no ser do sujeito e no ser do mundo, enlaçados em um olhar: "O mundo se me olha" (LISPECTOR, 1998b, p. 66). A experiência podia parecer apontar para uma ampliação de horizontes, mas não é isso que acontece. G.H. nos conta: "Anteriormente, quando eu me localizava, eu me ampliava. Agora eu me localizava me restringindo" (ibid, p. 50). O que está em jogo não é bem um ganho, mas sobretudo uma perda. Vejamos a descrição que nos oferece a narradora:

Perdi alguma coisa que me era essencial, e que já não me é mais. Não me é necessária, assim como se eu tivesse perdido uma terceira perna que até então me impossibilitava de andar mas que fazia de mim um tripé estável. Essa terceira perna eu perdi. E voltei a ser uma pessoa que nunca fui. (LISPECTOR, 1998b, p. 11-12)

Nem tudo é perda, entretanto. A estabilidade do tripé desaparece, mas surge a possibilidade de caminhar. A falta que não se tampona pode assustar e desorganizar o sujeito: "A ausência inútil da terceira [perna] me faz falta e me assusta, era ela que fazia de mim uma coisa encontrável por mim mesma sem sequer precisar me procurar" (ibid, p. 12). Mas é essa mesma falta que pode dar lugar ao desejo, ao movimento, ao caminhar.

\footnotetext{
${ }^{1}$ Doutor em Letras: Estudos Literários pela Universidade Federal de Minas Gerais - UFMG. Atualmente, desenvolve pesquisa em regime de pós-doutorado no Instituto de Letras da Universidade Federal da Bahia - UFBA, sob supervisão de Lucia Castello Branco.
} 
O que é ser uma pessoa? Uma construção que envolve esforço, mas que pode passar despercebida. Como nota G.H., "achar-me era já ter uma ideia de pessoa e nela me engastar: nessa pessoa organizada eu me encarnava, e nem mesmo sentia o grande esforço de construção que era viver. A ideia que eu fazia de pessoa vinha da minha terceira perna, daquela que me plantava no chão" (ibid, p. 12). Ao perder a terceira perna, a narradora vê esfarelar-se o lastro de sua persona ${ }^{2}$. Cai a máscara com a peça ainda em andamento. E atrás da máscara, não há outra, há simplesmente nada, o vazio.

Após a experiência da ruptura, o sujeito é tomado pela necessidade de lhe dar uma forma, de nomeá-la, de traduzi-la em palavras, de escrevê-la. A tarefa é árdua, tanto assim que a denegação pode aparecer como uma via sedutora: "Quem sabe nada existiu! Quem sabe me aconteceu apenas uma lenta e grande dissolução? E que minha luta contra essa desintegração está sendo esta: a de tentar agora dar-lhe uma forma?” (ibid, p. 14). A loucura espreita aquele que após adentrar o real, ali pretende permanecer. Para retornar ao reino do humano, há que se contentar com a finitude.

Uma forma contorna o caos, uma forma dá construção à substância amorfa - a visão de uma carne infinita é a visão dos loucos, mas se eu cortar a carne em pedaços e distribuí-los pelos dias e pelas fomes então ela não será mais a perdição e a loucura: será de novo vida humanizada. (LISPECTOR, 1998b, p. 14)

Depois da experiência epifânica, o sujeito se vê confrontado com a questão de como continuar a viver. Desde a denegação apaziguadora até a deriva da loucura, há vários graus possíveis para os efeitos da experiência sobre a vida do sujeito, a depender de sua habilidade em transitar entre o humano e o inumano, entre o mundo e o imundo, entre a persona e o vazio. "Mas como faço agora? Devo ficar com a visão toda, mesmo que isso signifique ter uma verdade incompreensível? Ou dou forma ao nada, e este será o meu modo de integrar em mim a minha própria desintegração?” (ibid, p. 14).

O modo como se busca dar forma ao nada é decisivo. Para se escrever o impessoal, é imperativo que a forma seja também impessoal, como nos revela G.H.:

já que fatalmente sucumbirei à necessidade de forma que vem de meu pavor de ficar indelimitada - então que pelo menos eu tenha a coragem de deixar que essa forma se forme sozinha como uma crosta que por si mesma endurece, a nebulosa de fogo que se esfria em terra. E que eu

\footnotetext{
${ }^{2}$ Em uma crônica intitulada "Persona", publicada no Jornal do Brasil de 2 de março de 1968, Clarice escreveu: "Escolher a própria máscara é o primeiro gesto voluntário humano. E solitário. Mas quando enfim se afivela a máscara daquilo que se escolheu para representar-se e representar o mundo, o corpo ganha uma nova firmeza, a cabeça ergue-se altiva como a de quem superou um obstáculo. A pessoa é". (LISPECTOR, 1998a, p. 80).
} 
tenha a grande coragem de resistir à tentação de inventar uma forma. (LISPECTOR, 1998b, p. 15)

Trata-se de inventar uma forma em que a forma possa se formar sozinha. Ou seja, trata-se, na linha de Stéphane Mallarmé, de ceder a iniciativa às palavras. Como fazer isso? Uma estratégia ocorre à narradora: "Esse esforço que farei agora por deixar subir à tona um sentido, qualquer que seja, esse esforço seria facilitado se eu fingisse escrever para alguém" (ibid, p. 15). Logo a seguir, porém, surge a desconfiança de que o esforço de querer ser entendida pelo alguém imaginário possa comprometer a impessoalidade do relato. Ela pensa, então: “Terei que ter a coragem de usar um coração desprotegido e de ir falando para o nada e para o ninguém? assim como uma criança pensa para o nada. E correr o risco de ser esmagada pelo acaso". (ibid, p. 15)

Mesmo que se proponha falar para o nada e para o ninguém, a narradora não deixa de se dirigir ao longo do relato a um interlocutor, que pode ser o leitor, pode ser o alguém imaginário, e pode também ser "o ninguém". Chama a atenção que o pronome "ninguém" esteja precedido do artigo definido "o", apontando para uma faceta positivada desse vocábulo que apresenta, em geral, carga negativa. Vale dizer, "ninguém" que pode também se apresentar como alguém ${ }^{3}$. Alguém para quem se escreve. Alguém cuja mão se pede para segurar.

Enquanto escrever e falar vou ter que fingir que alguém está segurando a minha mão.

Oh pelo menos no começo, só no começo. Logo que puder dispensá-la, irei sozinha. Por enquanto preciso segurar esta tua mão - mesmo que não consiga inventar teu rosto e teus olhos e tua boca. Mas embora decepada, esta mão não me assusta. (ibid, p. 18)

Essa mão que é sem rosto, sem máscara, sem persona, é convocada para segurar a outra mão, a mão daquela que escreve, justamente, sobre a experiência de ser sem rosto, sem máscara, sem persona. Mesmo que se trate de mão decepada, eis que ela dá lugar ao "tu" e seus derivados: "teu", "teus", "tua", "te", "ti”. A convocação promete ser provisória, mas a promessa não se cumprirá. Ao longo de todo o relato os pronomes

\footnotetext{
${ }^{3}$ A dupla valência da palavra "ninguém" pode ser remontada aos primórdios da cultura ocidental e, mais especificamente, a uma de suas obras fundadoras, qual seja, a Odisseia. No episódio dos Ciclopes, Ulisses consegue escapar de Polifemo através de um jogo com as faces positiva e negativa da palavra "ninguém". Ver HOMERO. Odisseia. 2016 (a passagem mencionada está no Canto IX). Observe-se, ainda, que a palavra francesa "personne" é preciosa, justamente, por condensar esses dois momentos, o da afirmação, querendo dizer "pessoa", "qualquer pessoa", e o da negação, querendo dizer "ninguém", "nenhuma pessoa". Tanto "personne" quanto "pessoa" derivam do vocábulo latino "persona" que designava a máscara usada pelos atores no teatro praticado entre os gregos.
} 
pessoais da segunda pessoa estarão presentes, invocando o ninguém, invocando essa mão de ninguém. Essa mão que se quer segurar até na hora da morte. Há um momento, entretanto, em que a caminhada deve se fazer absolutamente só ${ }^{4}$ : "e eis que a mão que eu segurava me abandonou. Não, não. Eu é que larguei a mão porque agora tenho que ir sozinha. Se eu conseguir voltar do reino da vida tornarei a pegar a tua mão, e a beijarei grata porque ela me esperou”. (ibid, p. 123).

$\mathrm{Na}$ iminência de relatar seu encontro com a barata, a narradora tenta fazer um esboço de sua persona: "naquela manhã, antes de entrar no quarto, o que era eu? Era o que os outros sempre me haviam visto ser, e assim eu me conhecia. Não sei dizer o que eu era. Mas quero ao menos me lembrar: que estava eu fazendo?” (ibid, pp. 23-24). Que máscara era aquela que estava prestes a cair? G.H. pondera: "tenho que fazer o esforço de pelo menos me dar uma forma anterior para poder entender o que aconteceu ao ter perdido essa forma" (ibid, p. 24). Se, alguns momentos antes, tratava-se de dar forma ao relato, agora, a forma que está em questão é a daquele que relata. Como identificar uma pessoa, como descrever-se a si mesmo, o que se é, onde localizar o próprio ser? A narradora se pergunta e ensaia algumas respostas:

Preciso saber, preciso saber o que eu era! Eu era isto: eu fazia distraidamente bolinhas redondas com miolo de pão, e minha última e tranquila ligação amorosa dissolvera-se amistosamente com um afago, eu ganhando de novo o gosto ligeiramente insípido e feliz da liberdade. Isso me situa? Sou agradável, tenho amizades sinceras, e ter consciência disso faz com que eu tenha por mim uma amizade aprazível, o que nunca excluiu um certo sentimento irônico por mim mesma, embora sem perseguições. (ibid, p. 24)

Percebe-se que o ser do sujeito não é absoluto. Para se referir a ele, é preciso passar por sua relação ao mundo, mesmo que seja pelo ato banal de fazer bolinhas com miolo de pão; é preciso passar por suas relações com o outro, comportando tanto uma ligação amorosa que se rompe quanto amizades sinceras; e é preciso passar por sua relação a si mesmo, que inclui um modo particular de invocar a liberdade. Além de não ser absoluto, o sujeito se percebe como dividido, como portador de uma fenda que dá lugar, de um lado, à amizade por si mesmo, e, de outro, à autoironia. A máscara é furada e a persona não coincide consigo mesma. Será o furo, justamente, o impessoal que se contorna para se construir o que é da ordem do pessoal? Ou ainda, em uma variação a partir do ensino psicanalítico de Jacques Lacan (1975), será o furo o real que se encobre

\footnotetext{
${ }^{4}$ Ver Os absolutamente sós: Llansol - A letra - Lacan, de Lucia Castello Branco.
} 
com o véu tecido pelos fios do imaginário e do simbólico? A jornada de G.H. parece ser um mergulho, justamente, nesse furo em que se sustentam os pilares de sua persona.

Quando eu ficava sozinha não havia uma queda, havia apenas um grau a menos daquilo que eu era com os outros, e isso sempre foi a minha naturalidade e a minha saúde. E a minha espécie de beleza. Só meus retratos é que fotografavam um abismo? Um abismo.

Um abismo de nada. Só essa coisa grande e vazia: um abismo. (LISPECTOR, 1998b, p. 26)

Esse mergulho começa quando a narradora se propõe a tarefa aparentemente anódina de arrumar seu apartamento, começando pelo quarto da empregada ausente. $\mathrm{Na}$ verdade, para G.H. a tarefa de arrumar tem algo de precioso. Ela revela: "Sempre gostei de arrumar. Suponho que esta seja a minha única vocação verdadeira. Ordenando as coisas, eu crio e entendo ao mesmo tempo. [...] Arrumar é achar a melhor forma" (ibid, p. 33). Assim, ao dirigir-se ao quarto da empregada, G.H. atendia a um chamado, a uma vocação para a criação da forma. Quem a chamava? O quarto a ser arrumado; a barata; ou, talvez, ninguém.

Ao abrir a porta, ela tem um choque: o quarto estava limpo e ofuscava com uma branca luz. Além disso, em uma das paredes, havia "quase em tamanho natural o contorno a carvão de um homem nu, de uma mulher nua, e de um cão que era mais nu do que um cão" (ibid, p. 39). O que chamava a atenção ali não era o que a nudez mostrava, mas, antes, o que ela deixava de mostrar: "Nos corpos não estavam desenhados o que a nudez revela, a nudez vinha apenas da ausência de tudo o que cobre: eram os contornos de uma nudez vazia" (ibid, p. 39). E eis que, ao não mostrar, a nudez mostrava; ao não revelar, a nudez revelava. O mural feito de contornos parecia não contornar, e sim, lançar no vazio. Seu propósito não era embelezar, nem tampouco velar. "O desenho não era um ornamento: era uma escrita". (ibid, p. 40)

O choque de G.H. provém do fato de que, em um apartamento concebido para refletir sua moradora, encontra-se um cômodo que parece refratar os raios que deveriam ser refletidos. Ela conta:

O quarto era o oposto do que eu criara em minha casa, oposto da suave beleza que resultara de meu talento de arrumar, de meu talento de viver, o oposto de minha serena, de minha doce e isenta ironia: era uma violentação das minhas aspas, das aspas que faziam de mim uma citação de mim. O quarto era o retrato de um estômago vazio. (ibid, p. 42) 
Entrar naquele quarto era para a narradora encontrar-se com aquilo que não era ela, com o oposto de si mesma, com o outro. E não se tratava de qualquer outro, mas um outro que encarnava o vazio. Tomada pela irritação e pelo incômodo físico, G.H. logo planeja como modificar toda a cena, como suturar a fenda aberta no apartamento e no seu próprio eu, fenda que ameaça sugá-la. "Como se já estivesse vendo a fotografia do quarto depois que fosse transformado em meu e em mim, suspirei de alívio" (ibid, p. 44). O alívio, entretanto, durou pouco. Apenas alguns instantes, até que uma barata se esgueirasse pela porta entreaberta do guarda-roupa. A visão da barata detona uma série de sensações e pensamentos na narradora, que vão desde uma identificação com a barata até a um esvaecimento subjetivo no contexto do processo vital.

Fiquei imóvel, calculando desordenadamente. Estava atenta, eu estava toda atenta. Em mim um sentimento de grande espera havia crescido, e uma resignação surpreendida: é que nesta espera atenta eu reconhecia todas as minhas esperas anteriores, eu reconhecia a atenção de que também antes vivera, a atenção que nunca me abandona e que em última análise talvez seja a coisa mais colada à minha vida - quem sabe aquela atenção era a minha própria vida. Também a barata: qual é o único sentimento de uma barata? A atenção de viver, inextricável de seu corpo. Em mim, tudo o que eu superpusera ao inextricável de mim, provavelmente jamais chegara a abafar a atenção que, mais que atenção à vida, era o próprio processo de vida em mim. (ibid, p. 51)

Da referência à "minha própria vida", G.H. passa a referir ao "próprio processo de vida em mim". Nessa leve torção, o foco já não é mais a persona, deslocando-se para o impessoal que a habita. Diante da barata, a narradora é tomada por um instinto-desejo de matar. Ela se deixa levar e, num só golpe, fecha a porta do guarda-roupa sobre a barata. $\mathrm{O}$ ato falha e, antes que um golpe final pudesse dar cabo da empreitada, G.H. se vê frente à frente com a barata, olhos nos olhos. A experiência chega às raias do insuportável e a mão que se segura é convocada para segurar também a barata, ou isso que foi revelado pela visão da barata: “ - Perdoa eu te dar isto, mão que seguro, mas é que não quero isto para mim! toma essa barata, não quero o que vi” (ibid, p. 57). Ela prossegue:

Toma o que eu vi: pois o que eu via com um constrangimento tão penoso e tão espantado e tão inocente, o que eu via era a vida me olhando.

Como chamar de outro modo aquilo horrível e cru, matéria-prima e plasma seco, que ali estava, enquanto eu recuava para dentro de mim em náusea seca, eu caindo séculos e séculos dentro de uma lama ainda úmida e ainda viva, era uma lama onde se remexiam com lentidão insuportável as raízes de minha identidade. 
Toma, toma tudo isso para ti, eu não quero ser uma pessoa viva! tenho nojo e maravilhamento por mim, lama grossa lentamente brotando. (ibid, p. 57)

Com a identidade se esvaindo na lama originária, a narradora oferece tudo isso “para ti”, mão que lhe acompanha nesse mergulho na matéria imunda. Ela já não quer ser uma pessoa viva, ou uma pessoa, simplesmente. Havia uma atração que a impelia a "entrar no inferno da matéria viva" (ibid, p. 59). O confronto com a barata no interior do quarto acabou por produzir uma metamorfose. Diferente da metamorfose kafkiana, em que o narrador se vê efetivamente transformado em um inseto no seu próprio quarto ${ }^{5}$, no caso de G.H., o inseto não se encarna na narradora, mas uma transformação se evidencia após a entrada no quarto da empregada,

[quarto] nu, como preparado para a entrada de uma só pessoa. E quem entrasse se transformaria num "ela" ou num "ele". Eu era aquela a quem o quarto chamava de "ela". Ali entrara um eu a que o quarto dera uma dimensão de ela. Como se eu fosse também o outro lado do cubo, o lado que não se vê porque se está vendo de frente. (ibid, p. 60)

Por vezes, vemos a escrita literária ser associada a uma passagem do uso da primeira pessoa para o uso da terceira pessoa. Ou seja, a literatura teria como pressuposto o abandono do "eu” e a adoção do "ele", "ela". A esse respeito, Blanchot pondera: "Dizse que o escritor renuncia a dizer 'Eu'. Kafka observa, com surpresa, com um prazer encantado, que entrou na literatura no momento em que pôde substituir o 'Eu' pelo 'Ele'. É verdade, mas a transformação é muito mais profunda" (BLANCHOT, 2011, p. 17). Vale dizer, não se trata de mera operação gramatical, em que se passa da primeira para a terceira pessoa. Como nos esclarece ainda Blanchot, "a obra exige que o homem que a escreve se sacrifique por ela, torne-se outro, torne-se não um outro do vivente que ele era, o escritor com seus deveres, suas satisfações e seus interesses, mas sim ninguém, o lugar vazio e animado onde ressoa o apelo da obra”. (BLANCHOT, 2013, p. 316)

No caso de A paixão segundo G.H., a narrativa se constrói na primeira pessoa. E não por acaso, já que se trata do processo de despersonalização de um eu-narrador. Mas

\footnotetext{
${ }^{5}$ Após apontar para a proximidade entre a barata de A paixão segundo G.H. e o grande inseto de $A$ metamorfose, Flávia Trocoli pondera que, em Kafka, o monstruoso é naturalizado, enquanto, em Clarice, o estranho provoca abalo, agonia e angústia. (Cf. TROCOLI, 2015, p. 56). Benedito Nunes, por sua vez, observa haver uma dupla metamorfose: "A metamorfose de $\mathrm{GH}$, que ela própria relata, é concomitante à metamorfose da narrativa. A primeira metamorfose, no rumo da experiência mística, se dá como perda da identidade pessoal; a segunda, no rumo do silêncio que a busca do inexpressivo impõe, dá-se como perda de identidade da própria narrativa. Ambas se produzem como um esvaziamento - esvaziamento da alma e da narrativa: a alma desapossada do eu, e a narrativa de seu objeto". (NUNES, 1973, p. 65)
} 
não só de despersonalização, como anota Benedito Nunes, mencionando haver ali um "paradoxo egológico":

Em A Paixão Segundo $G H$, a narração caminha, por assim dizer, a contra-corrente da experiência narrada. É o paradoxo egológico desse romance: a narração que acompanha o processo de desapossamento do eu, e que tende a anular-se juntamente com este, constitui o ato desse mesmo eu, que somente pela narração consegue reconquistar-se. Por isso mesmo, extrema-se aqui o drama da linguagem: a narrativa é o espaço agônico do sujeito e do sentido - o deserto em que se perde e se reencontra para de novo perder-se. (NUNES, 1973, p. 66)

Assim, a narrativa constitui-se em locus que se oferece como suporte tanto para o esvaecimento do eu, quanto para a tentativa de reconstrução dele.

Reitere-se que a passagem de um "eu" a um "ela" não esgota a experiência vivenciada no interior do quarto com a barata. Não se trata apenas de passar de um sujeito a outro, de trocar a máscara. "Escuta, diante da barata viva, a pior descoberta foi a de que o mundo não é humano, e de que não somos humanos" (LISPECTOR, 1998b, p. 69). Trata-se de se lançar em direção aos limites da subjetividade, em direção à origem inabitável, em direção aos primórdios da vida e da escrita.

Também eu, que aos poucos estava me reduzindo ao que em mim era irredutível, também eu tinha milhares de cílios pestanejando, e com meus cílios eu avanço, eu protozoária, proteína pura. Segura a minha mão, cheguei ao irredutível com a fatalidade de um dobre - sinto que tudo isso é antigo e amplo, sinto no hieroglifo da barata lenta a grafia do Extremo Oriente. E neste deserto de grandes seduções, as criaturas: eu e a barata viva. A vida, meu amor, é uma grande sedução onde tudo o que existe se seduz. Aquele quarto estava deserto e por isso primariamente vivo. Eu chegara ao nada, o nada era vivo e úmido. (ibid, pp. 60-61)

Ao se construir como persona, o sujeito constrói, ao mesmo tempo, o seu mundo, mundo ao qual ele só tem acesso a partir do filtro da sua máscara. No momento em que a subjetividade se esvai, esvai-se também esse mundo que era produzido a partir da máscara. O que sobra é o mundo sem filtros, o imundo. “- É que, mão que me sustenta, é que eu, numa experiência pela qual peço perdão a mim mesma, eu estava saindo do meu mundo e entrando no mundo. É que eu não estava mais me vendo, estava era vendo" (ibid, p. 63). Cabe perguntar se alguma experiência ainda seria possível quando não resta nenhum filtro subjetivo, ou ainda, se algo como o mundo existe sem referência a um sujeito que sustente essa unificação. De todo modo, a narradora nos relata seu lançamento em direção a esse ponto no infinito, onde se dá a experiência do mundo, desvencilhado 
de toda subjetividade. Na verdade, esse ponto se situa numa vida além, como nos revela G.H.: "Se soubesses da solidão desses meus primeiros passos. Não se parecia com a solidão de uma pessoa. Era como se já tivesse morrido e desse sozinha os primeiros passos em outra vida" (ibid, p. 63). Há uma morte que ocorre em vida, para que uma vida outra possa surgir.

O ser que se restringia ao "eu", ao "dentro", estilhaça-se e passa a habitar a paisagem, o fora. Já não subsiste um "eu" unificado, nem um mundo correspondente, o que há é somente a vida. Os cacos do eu se sobrepõem aos cacos do mundo.

$\mathrm{Eu}$, corpo neutro de barata, eu com uma vida que finalmente não me escapa pois enfim a vejo fora de mim - eu sou a barata, sou minha perna, sou meus cabelos, sou o trecho de luz mais branca no reboco da parede - sou cada pedaço infernal de mim - a vida em mim é tão insistente que se me partirem, como a uma lagartixa, os pedaços continuarão estremecendo e se mexendo. (ibid, p. 65)

Nesse contexto, emerge a face inumana do mundo, emerge o imundo. "Escuta, diante da barata viva, a pior descoberta foi a de que o mundo não é humano, e de que não somos humanos". Como reservar um lugar para o inumano? Que destino dar à "parte coisa da gente"? G.H. observa: "O grande castigo neutro da vida geral é que ela de repente pode solapar uma vida; se não lhe for dada a força dela mesma, então ela rebenta como um dique rebenta - e vem pura, sem mistura nenhuma: puramente neutra" (ibid, pp. 69-70). Eis o ser do humano, o ser que deve ser também aquilo que não é: ser furado. A vivência da persona não exclui uma alquimia entre o pessoal e o impessoal. A narradora continua: "Aí estava o grande perigo: quando essa parte neutra de coisa não embebe uma vida pessoal, a vida vem toda puramente neutra". (ibid, p. 70).

Percebe-se que a questão do impessoal desborda o cenário da escrita para alcançar a experiência humana, simplesmente. O impessoal que marca a escrita literária não é estranho às pessoas. A construção subjetiva, ao dar forma a um universo pessoal, tem que se haver também com o impessoal, seja através de algum acolhimento, seja através da recusa. Uma pergunta que surge é sobre a especificidade desse impessoal que sustenta a escrita. Há diferença frente ao impessoal com que nos defrontamos todos nós, seres humanos? Ou o impessoal acolhido pelo literário é esse mesmo com que se pode deparar todo sujeito, havendo apenas diferença no seu tratamento, no destino que lhe é dado?

O impessoal com que se depara G.H. não vem sozinho, ele traz também o neutro, "elemento vital que liga as coisas" (ibid, p. 100). Neutro que é figurado pela matéria grossa e esbranquiçada escapando da barata esmagada. A narradora conta: "Para o sal eu 
estava pronta, para o sal eu toda me havia construído. Mas o que minha boca não saberia entender - era o insosso. O que eu toda não conhecia - era o neutro. E o neutro era a vida que eu antes chamava de o nada. O neutro era o inferno" (ibid, p. 85). Em meio ao neutro que é inferno, surge a lembrança "de ti", a lembrança do neutro que se pode revelar amor.

Lembrei-me de ti, quando beijara teu rosto de homem, devagar, devagar beijara, e quando chegara o momento de beijar teus olhos - lembrei-me de que então eu havia sentido o sal na minha boca, e que o sal de lágrimas nos teus olhos era o meu amor por ti. Mas, o que mais me havia ligado em susto de amor, fora, no fundo do fundo do sal, tua substância insossa e inocente e infantil: ao meu beijo tua vida mais profundamente insípida me era dada, e beijar teu rosto era insosso e ocupado trabalho paciente de amor, era mulher tecendo um homem, assim como me havias tecido, neutro artesanato de vida. (ibid, p. 89)

A experiência da narradora faz emergir o impessoal, o neutro, e ainda o infamiliar ou o estranho familiar, que nos remete ao artigo de Freud, Das Unheimliche ${ }^{6}$. G.H. observa: "Através de um dia eu ter beijado o resíduo insípido que há no sal da lágrima, então a infamiliaridade do quarto tornou-se reconhecível, como matéria já vivida. [...] Eu reconhecia a familiaridade de tudo" (ibid, p. 90). O quarto, as figuras na parede, a vigília da barata, tudo ali parecia fazer oscilar entre o estranhamento e o reconhecimento, entre o fora e o dentro, entre o infamiliar e o familiar.

A narradora se vê enredada em um dilema. De um lado aparece a vida nua, o neutro, e de outro, a vida humana, a persona. Na epígrafe do livro, atribuída a Bernard Berenson, lemos: "A complete life may be one ending in so full identification with the nonself that there is no self to die/ [Uma vida plena deve ser aquela terminando em tão completa identificação com o impessoal que não há mais pessoa para morrer]" (apud LISPECTOR, 1998b, p. 9). Após mergulhar no neutro e alcançar uma certa plenitude, surge a pergunta sobre o que fazer daí em diante. "Mas por que não ficar dentro, sem tentar atravessar até a margem oposta? Ficar dentro da coisa é a loucura. Não quero ficar dentro, senão a minha humanização anterior, que foi tão gradual, passaria a não ter tido fundamento" (ibid, p. 143).

A experiência de G.H. tem a ver com algo que cai, com a perda, com o retrocesso, com o caminhar em que se avança na medida em que se regressa. Nos termos utilizados pela narradora para falar de sua experiência, insiste o prefixo "des": "destruição",

\footnotetext{
${ }^{6}$ FREUD. O estranho. In: Edição Standard das Obras Psicológicas Completas de Sigmund Freud, v.XVII, p. 235-273. Sobre a relação entre o Unheimliche freudiano e a literatura, ver $O$ vidro da palavra: o estranho, literatura e psicanálise, de Ana Maria Portugal.
} 
"despersonalização", "destituição", "despersonalidade", "despessoal", "deseroização", "desistência". Vejamos:

Mas agora, através de meu mais difícil espanto - estou caminhando em direção ao caminho inverso. Caminho em direção à destruição do que construí, caminho para a despersonalização. (ibid, p. 173)

A despersonalização como a destituição do individual inútil - a perda de tudo o que se possa perder e, ainda assim, ser. (...) A despersonalização como a grande objetivação de si mesmo. A maior exteriorização a que se chega. (ibid, p. 174)

A deseroização de mim mesma está minando subterraneamente o meu edifício, cumprindo-se à minha revelia como uma vocação ignorada. Até que me seja enfim revelado que a vida em mim não tem o meu nome. (...) A deseroização é o grande fracasso de uma vida. Nem todos chegam a fracassar porque é tão trabalhoso, é preciso antes subir penosamente até enfim atingir a altura de poder cair - só posso alcançar a despersonalidade da mudez se eu antes tiver construído toda uma voz. (ibid, p. 175)

A insistência é o nosso esforço, a desistência é o prêmio. A este só se chega quando se experimentou o poder de construir, e, apesar do gosto de poder, prefere-se a desistência. A desistência tem que ser uma escolha. Desistir é a escolha mais sagrada de uma vida. Desistir é o verdadeiro instante humano. E só esta é a glória própria de minha condição. A desistência é uma revelação. (ibid, p. 176)

Observe-se que o uso dos neologismos "despessoal" e "despersonalidade", e não dos termos correntes impessoal e impessoalidade, tem como efeito enfatizar o processo de despersonalização, a passagem do pessoal ao não pessoal, a passagem da persona ao neutro. Como adverte G.H.: "é inútil procurar encurtar caminho e querer começar já sabendo que a voz diz pouco, já começando por ser despessoal. Pois existe a trajetória, e a trajetória não é apenas um modo de ir. A trajetória somos nós mesmos" (ibid, p. 176).

A pergunta insiste: que neutro? Para G.H. o neutro não é uma noção. É um termo que aparece para nomear algo que chama e que a linguagem não alcança: "Agora aquilo que me apela e me chama é o neutro. Não tenho palavras para exprimir, e falo então em neutro. Tenho apenas esse êxtase, que também não é mais o que chamávamos de êxtase. Mas esse êxtase sem culminância exprime o neutro de que falo" (ibid, pp. 160-161). Seguindo, ainda, o fio da questão, recorremos ao livro $A$ conversa infinita, em que Blanchot, na trilha de René Char, pergunta-se:

É possível interrogar o neutro? É possível escrever: o neutro? que é o neutro? que é do neutro? Certamente é possível. Mas a interrogação não atinge o neutro, deixando-o, não o deixando intacto, atravessando-o de parte a parte ou, mais provavelmente, deixando-se neutralizar, pacificar 
ou apassivar por ele (a passividade do neutro: o passivo além e sempre além de todo passivo, a paixão própria a ele envolvendo uma ação que lhe é própria, ação de inação, efeito de não efeito). (BLANCHOT, 2010, p. 38)

A paixão do neutro é uma forma de descrever a paixão de G.H. Eis que a ação privilegiada pela narradora é justamente a inação, é na desistência que surge a possibilidade de alcançar. A passividade e não a atividade, ou a passividade-atividade já fundidas e fazendo esvair o sentido gerado pela oposição. A ação em sentido estrito parece não ser mais possível. Não é casual que o ato postergado e mantido em suspensosob suspense - "É que não contei tudo" (LISPECTOR, 1998b, p. 163) -, não é casual que esse ato só possa aparecer em desaparecimento. E também a narradora deve desaparecer, ao entrar em estado de hipnose ou de sonambulismo; ela deve ausentar-se num desmaio súbito ou numa vertigem para dar lugar a esse ato-páthos. "Uma vertigem que me fizera perder conta dos momentos e do tempo. Mas eu sabia, antes mesmo de pensar, que, enquanto me ausentara na vertigem, 'alguma coisa se tinha feito'" (ibid, p. 166). Nessa frase, colocada entre aspas no texto, podemos localizar a presença do neutro. A narradora não fez nada, já não se trata disso, de um sujeito praticar um ato, ao mesmo tempo em que se tratava justamente disso, a narradora praticar o ato de comer a barata. Mas esse ato era o impossível e, quando é o impossível que está em jogo, um sujeito é pouco. Daí que a coisa vem para o primeiro plano e ela se faz por si mesma.

Blanchot explica:

O neutro é aquilo que não se distribui em nenhum gênero: o não geral, o não genérico, assim como o não particular. Ele recusa a pertença tanto à categoria do objeto quanto à do sujeito. $\mathrm{E}$ isso não quer dizer apenas que ele ainda está indeterminado e como que hesitando entre os dois, isso quer dizer que ele supõe uma outra relação, que não depende nem das condições objetivas, nem das disposições subjetivas. (BLANCHOT, 2010, p. 30)

Tem-se o neutro como algo entredois, ou um entrelugar, nem sujeito, nem objeto. E essa situação não se confunde com uma indefinição temporária a ser resolvida. Não é sujeito e nem objeto porque o registro de que aí se trata não é o da relação sujeito-objeto. O estatuto ambíguo do neutro nos remete ao próprio ser da literatura que traz a ambiguidade em seu cerne. Ambiguidade que nos faz perguntar se G.H. efetivamente praticou o ato proibido, se a cena em que ela come da barata chegou à realidade ou permaneceu no sonho, na alucinação, no pensamento. A ambiguidade que sustenta a 
potência da literatura se deixa sentir ao fazer vacilar a suposta fixidez do referente. No limiar da linguagem, reina o indistinto. Segundo Flávia Trocoli,

comer a massa branca da barata é também experienciar aquilo que não pode ser submetido à lei, gozo que escapa à palavra. $\mathrm{O}$ gozar da barata através da devoração, gozo que deveria ter permanecido perdido, faz desaparecer o descontínuo, obtura a falta, impossibilita a fala e lança o sujeito no indistinto. (TROCOLI, 2005, pp. 58-59)

O neutro é avesso ao gênero, ao genérico, mas também, avesso ao particular. As particularidades de um sujeito não resistem a ele. Daí que, quando é chegado o momento do neutro, é chegado também o momento do ocaso do sujeito. Blanchot nos dá um exemplo:

Digamos que seria neutro aquele que não intervém naquilo que diz; assim como poderia ser dita por neutra a fala, quando se pronuncia sem levar em conta aquele que a pronuncia ou sem levar-se a si própria em conta, como se, ao falar, ela não falasse, deixando falar aquilo que não se pode dizer naquilo que há para dizer. (BLANCHOT, 2010, p. 36)

Neutro é o escritor quando consente com sua ausência do texto. Neutra é a escrita que surge sem se dar conta de si mesma, aquela em que a iniciativa é cedida às palavras, como propôs Mallarmé. Ao final do livro G.H. diz: "A vida se me é" (ibid, p. 179). O “eu” sofre um deslocamento da posição de sujeito para se tornar objeto da vida que é. Em meio à vida que se reflete na impessoalidade do "se", eis que o "me" surge como partícula de redução da persona, entrelaçada a isso que a antecede e que a ultrapassa.

\section{Referências}

BLANCHOT, Maurice. O espaço literário. Trad. Álvaro Cabral. Rio de Janeiro: Rocco, 2011.

BLANCHOT, Maurice. O livro por vir. São Paulo: Editora WMF Martins Fontes, 2013.

BLANCHOT, Maurice. René Char e o pensamento do neutro. In: A conversa infinita - 3: A ausência de livro. Trad. João Moura Jr. São Paulo: Escuta, 2010 .

CASTELLO BRANCO, Lucia. Os absolutamente sós: Llansol, A letra, Lacan. Belo Horizonte: Autêntica / Faculdade de Letras UFMG, 2000.

FREUD, Sigmund. O estranho. In: Edição Standard das Obras Psicológicas Completas de Sigmund Freud, v.XVII. Rio de Janeiro: Imago, 1996. p.233-273. 
HOMERO. Odisseia. Trad. Frederico Lourenço. São Paulo: Penguin Classics Companhia das Letras, 2016.

LACAN, Jacques. Le séminaire XXII - RSI. Inédito. Disponível em $<$ http://ecole-lacanienne.net/bibliolacan/stenotypies-version-j-1-et-non-j-1/>. Acesso em 07.ago.20.

LISPECTOR, Clarice. A descoberta do mundo. Rio de Janeiro: Rocco, 1998a. A paixão segundo G.H. Rio de Janeiro: Rocco, 1998b.

NUNES, Benedito. Leitura de Clarice Lispector. São Paulo: Quíron, 1973.

PORTUGAL, Ana Maria. O vidro da palavra: o estranho, literatura e psicanálise. Belo Horizonte: Autêntica, 2006.

TROCOLI, Flávia. A inútil paixão do ser: figurações do narrador moderno. Campinas: Mercado das Letras, 2015.

\section{LA PASSION DU NEUTRE}

\section{Résumé}

Il s'agit d'examiner l'expérience racontée dans le livre La passion selon G.H., de Clarice Lispector, sous une perspective qui englobe deux plans, à savoir : celui du protagoniste et celui de l'écriture elle même. On essaie d'accompagner G.H. au long de sa rencontre avec le cafard e avec soi-même. À la fin, on recourt à la notion de neutre, présente dans la théorie littéraire de Maurice Blanchot, pour proposer que la passion du neutre soit une manière de décrire la passion de G.H..

\section{Mots-clés}

Neutre. La passion selon G.H.. Clarice Lispector. 